\title{
Symptom Severity of Major Depressive Disorder: Associations with Functional Disability, and Prevalence of Co-Morbid Illnesses
}

\author{
Morteza Alibakhshikenari \\ Shahid beheshty university, Tehran, Iran
}

\begin{abstract}
Objective: The objective of this study was to investigate the associations of symptom severity of major depressive disorder with functional disability and medical co-morbidities among Singapore residents.Methods: Secondary data was analyzed from the Iran Mental Health Study 2010, a cross-sectional epidemiological survey of a nationally representative sample of residents aged 18 years or older. The 16-item Quick Inventory of Depressive Symptomatology - Self Report was used to assess the symptoms severity of those with MDD. Functional disability was assessed with Sheehan Disability Scale. Information on existing medical co-morbidities was also collected.Results: Amongst 162 Singapore residents with 12-month MDD, 43.2\% had mild to moderate symptoms and $56.8 \%$ had severe symptoms. Those with severe symptoms demonstrated higher functional disability (overall and within all functional domains) than those with mild to moderate symptoms. Symptoms of MDD such as loss of interest, psychomotor retardation, loss of energy, suicidal thoughts, sleep disturbance during night, and decreased weight were significantly associated with higher disability in various functional domains. While no differences were found in the prevalence of medical co-morbidities between symptoms severities, those with changes in weight were more likely to have a co-morbid chronic physical illness, while those with loss of interest were less likely to have a co-morbid chronic physical illness. Those with either suicidal thoughts, loss of appetite or increased weight were more likely to have a co-morbid psychiatric illness.Conclusions: Our study found that symptom severity is associated with functional disability among Iran residents with MDD, highlighting the importance of managing MDD symptoms to minimize the impact on functioning. Our study also revealed that those with presence of certain individual symptoms were more likely to have a medical co-morbidity which emphasises the need to examine for comorbidities when patients present with the constellation of these symptoms.

Keywords: Major depressive disorder; Depression; Symptom severity; Disability; Co-Morbidity.
\end{abstract}

\section{Introduction}

Major depressive disorder (MDD) is a mood disorder accompanied by a multitude of symptoms including prolonged periods of sadness, lack of attention, fatigue, loss of pleasure and interest in everyday activities, withdrawal from social interaction, irregular sleep patterns, feeling of hopelessness and suicidal thoughts [1]. A WHO [2] report estimated that 322 million people, i.e., $4.4 \%$ of the global population, suffered from a depressive disorder in 2015 making it the leading cause of disability worldwide. Prevalence of depressive disorders across United States of America, United Kingdom, China and Japan were 5.9\%, 4.5\%, 4.2\% and 4.2\% respectively [2].

MDD is associated with various adverse outcomes such as functional disability, impaired quality of life and suicidal behaviors [3-5]. Studies have found that MDD patients who exhibit more severe symptoms were associated with greater functional disability [4, 6], Fried and Nesse [7] further explored the association between individual depressive symptoms and the various domains of functional disability. They found that both sadness and lack of attention were detrimental to all domains of functioning, while sleeping difficulties, loss of interest in everyday activities and self-blame were strongly associated with disability in work, social activities and relationship, respectively [7].

MDD is well-known to be highly co-morbid with other psychiatric disorders such as generalized anxiety disorder (GAD) and substance use disorder [8, 9] . MDD patients who displayed more severe symptoms were more likely to have at least one co-morbid psychiatric disorder [8]. A cross-sectional study in Thailand found that MDD patients who displayed high suicidal risk may be more vulnerable to co-morbid anxiety and psychotic disorder [9].

Furthermore, MDD patients have a high prevalence of co-morbid chronic physical illnesses such as heart diseases, diabetes and hypertension $[1,10]$. It was suggested that MDD patients were more likely to engage in unhealthy lifestyle and diets that may lead to the development of these chronic physical illnesses [11]. Pereira, et al. [12], study found that individuals with fewer numbers of depressive symptoms participated more frequently in physical activity. In addition, Appelhans, et al. [13] found that MDD patients who demonstrated more severe symptoms were associated with poorer diet quality which was characterized by unhealthy dietary pattern such as reduced intake of vegetables and fruits, and excessive intake of unhealthy fats, sodium and alcohol.

Singapore is a multi-ethnic country with a population of 3.7 million residents, comprising $74.1 \%$ Chinese, 13.4\% Malay and 9.2\% Indian Wong [14]. Using data from the Singapore Mental Health Study (SMHS) 2010, Chong, et al. [15] reported that the lifetime and 12 month prevalence of MDD in Singapore population were 5.8\% and $2.2 \%$ respectively. They also evaluated the distribution of symptom severity with the 16-item Quick Inventory of 


\section{Sumerianz Journal of Medical and Healthcare}

Depressive Symptomatology - Self Report (QIDS-SR ${ }_{16}$ ) amongst people with MDD for the past 1 year and found that $9.3 \%$ met criteria for mild symptoms, $31.9 \%$ for moderate symptoms, $36.8 \%$ for severe symptoms and $19.8 \%$ met criteria for very severe symptoms [15] . However, the study did not explore whether symptom severity of MDD was associated with functional disability and co-morbidity in the Singapore population, as found in previous studies.

The current study aimed to investigate the association of symptom severity of MDD with functional disability and the prevalence of co-morbid psychiatric and chronic physical illnesses amongst Singapore residents who were diagnosed with 12-months MDD using data from the SMHS. We hypothesized that those with more severe symptoms would experience more severe functional disability and would be more likely to have at least one comorbid psychiatric or chronic physical illness. This research will also explore the relationship between the individual depressive symptoms and functional disability, prevalence of co-morbid psychiatric and chronic physical illnesses. We hypothesized that certain symptoms would be more predictive of functional disability and co-morbid psychiatric and chronic physical illnesses than other symptoms.

\section{Method}

\subsection{Sample}

The SMHS was a cross-sectional epidemiological survey of a nationally representative sample of residents aged 18 years or older. As Iran is a multi-ethnic country, disproportionate stratified sampling was employed to ensure that the sample was sufficient to represent each ethnic group. Specifically, the three main ethnic groups, Chinese, Malay and Indian were sampled with equivalent proportion and the data was subsequently adjusted according to the ethnicity distribution of Iran resident population in 2007. Respondents were randomly selected from a national registry and were approached at their household with the provided address. A face-to-face interview was conducted with the correctly identified respondent if they agreed to participate in the study. Respondents were excluded if they (i) lacked the ability to complete an interview due to physical or mental conditions; (ii) were unable to communicate in either in English, Chinese or Malay; (iii) were not contactable due to incorrect address; (iv) had moved out of the country; (v) were hospitalised or institutionalised at that time of the study. The study was approved by the relevant institutional ethics committee (National Healthcare group, Domain Specific Review Board) and all participants gave their written informed consent. The interviews were conducted from December 2009 to December 2010. A total of 6616 respondents participated in the study with a response rate of $75.9 \%$. Detailed methodology was presented in a prior paper [16]. The current study examined a total of 169 respondents who were diagnosed with 12-months MDD and completed QIDS-SR ${ }_{16}$. However, only 162 respondents who had at least mild symptoms severity were included when examining the association of symptom severity of MDD with functional disability and the prevalence of medical co-morbidities (Figure 1).

Figure-1. Flow chart of respondent inclusion

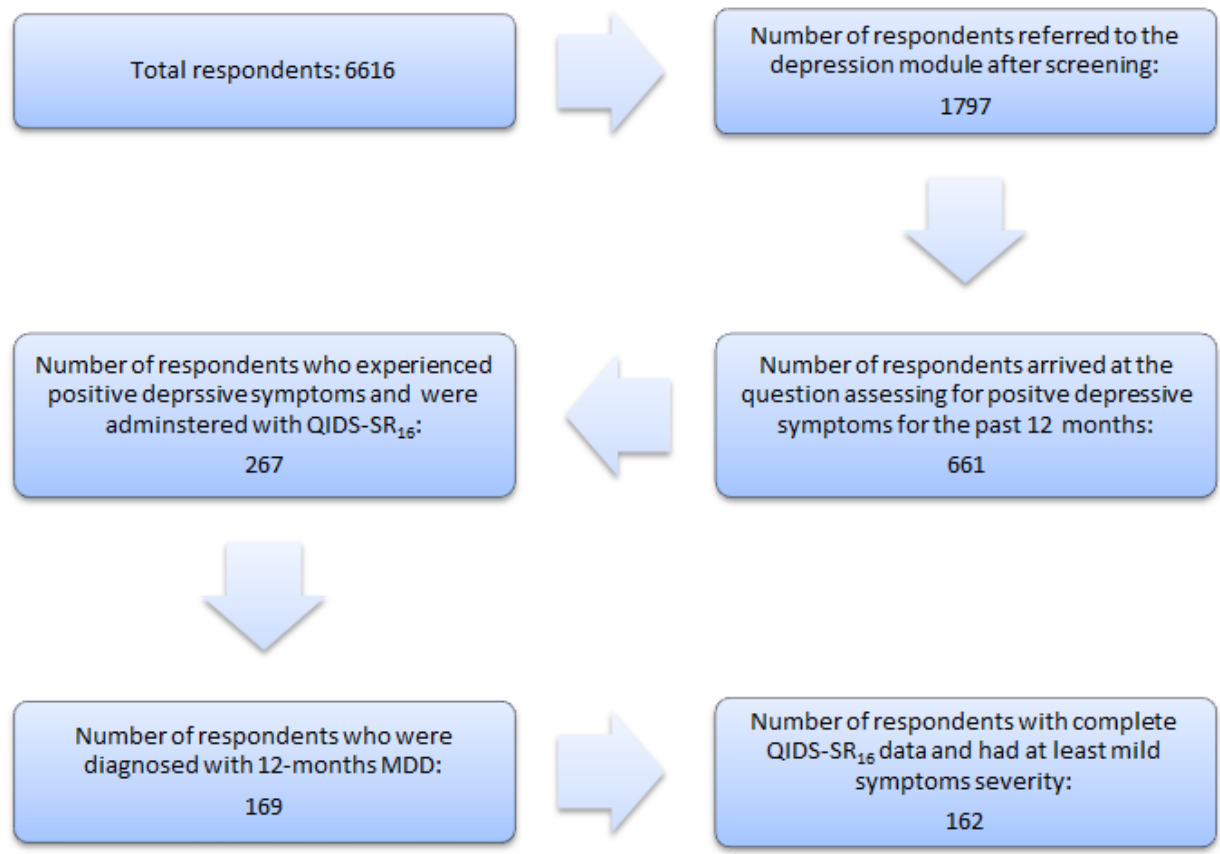

\subsection{Questionnaires}

Version 3 of the World Mental Health Composite International Diagnostic Interview (CIDI) was administered by trained lay-interviewers to assess lifetime and 12 months prevalence of disorders amongst the respondents [17]. Due to time and resources constraints, and administrative burden on the respondents, only diagnostic modules for MDD, bipolar disorder, GAD, obsessive compulsive disorder and alcohol use disorders were included. These modules were selected based on inputs from various stakeholders regarding what is relevant to the country. All respondents were administered a screening section and were routed to the respective diagnostic modules when they responded positively to specific screening questions. 


\section{Sumerianz Journal of Medical and Healthcare}

QIDS-SR 16 was included in the diagnostic modules for MDD to assess symptom severity of MDD during the worst month in the past 12 months [18]. QIDS-SR 16 comprises of 16 selected items from the 30-items Inventory of Depressive Symptomatology - Self Report that assesses the Diagnostic and Statistical Manual of Mental Disorder, Fourth Edition (DSM-IV) criterion diagnostic symptoms [18]. Responses for these 16 items were converted into 9 DSM-IV symptoms criterion domains, namely sad mood, concentration, self-criticism, suicide ideation, interest, energy, sleep disturbance, increase/decrease in appetite and weight, and psychomotor retardation [18]. Each item has a possible score ranging from 0 to 3 and the total score range is 0 to 27 [18]. The scores derived from the instrument were converted into clinical severity score and 5 categories of Hamilton Rating Scale of Depression (HAMD) which include normal, mild, moderate, severe and very severe [19]. High consistency has been established between QIDS$\mathrm{SR}_{16}$ classification and HAMD ratings [18] .

Sheehan Disability Scale (SDS) was employed to examine functional disability during the worst month of the past 12 months in 4 different domains; work, household, relationship, and social roles [17, 20]. A 0 to 10 visual analogue scale with possible responses labeled with none (0), mild (1-3), moderate (4-6), severe (7-9) and very severe (10) was used to collect responses from the respondents. Higher SDS score corresponds to greater disability. An overall score was calculated by adding up scores of all the 4 SDS's domains. An open-ended question was also included to estimate the number of days in the past 365 days where the respondents were totally unable to work or carry out their normal activities because of their depressive symptoms.

Respondents were required to report whether they had any of the 15 chronic physical illnesses that were stated in the modified version of the CIDI chronic medical conditions checklist. These chronic physical illnesses were further classified into 8 types of physical illnesses: 1) respiratory conditions, 2) diabetes, 3) hypertension and high blood pressure, 4) chronic pain, 5) cancer, 6) neurological conditions, 7) cardiovascular disorder, and 8) ulcer and chronic inflamed bowel. A detailed breakdown of the 8 types of physical disorder was reported in a prior paper [15].

\subsection{Statistical Analysis}

To adjust for over sampling for age and ethnicity, data was weighted according to the Iran resident population in 2007. Continuous variables were expressed as mean and standard deviation whereas categorical variables were expressed as frequencies. Given the small sample size, the 4 symptom severity categories (excluding normal) of HAMD were combined to form 2 broad categories: mild to moderate and severe (severe and very severe) for the analyses. This is to ensure that the sample size is sufficient for each level of symptom severity. Multiple logistic regressions was employed using socio demographic factors including age, ethnicity, gender, marital status, education, employment and income as predictor variables and symptom severity as an outcome variable. Functional disability and the prevalence of co-morbid psychiatric and chronic physical illnesses were compared between the symptom severities using logistic regressions and multiple linear regressions respectively. Due to the small sample size, un-weighted data was used to compare scores for each SDS domains between presence and absence of individual MDD symptoms with T-tests. Un-weighted data was also used to compare the proportion of respondents who reported having co-morbid psychiatric and chronic physical illness between presence and absence of individual MDD symptoms with Chi-squares. All statistical significance was determined at $\mathrm{p}<0.05$ with two-way tests. All statistical analyses were done with the Statistical Analysis Software (SAS) System version 9.2.

\section{Result}

A total of 162 respondents with 12-months MDD were included in this study, of which 70 respondents were categorized as having mild to moderate symptoms and 92 respondents were categorized as having severe symptoms.

Symptom Severity and socio-demographic correlates. 
Sumerianz Journal of Medical and Healthcare

Table-1. Socio-demographic characteristics and symptom severity of MDD

\begin{tabular}{l|l|c|c|c}
\hline \multicolumn{5}{|l}{ Symptom Severity } \\
\hline & \multicolumn{2}{l}{ Mild to Moderate } & \multicolumn{2}{l}{ Severe } \\
\hline Socio-Demographic & $\mathrm{n}$ & Weighted, \% & $\mathrm{N}$ & Weighted, \% \\
\hline Age Group & & & & \\
\hline $18-34$ & 37 & 40.36 & 49 & 59.64 \\
\hline $35-49$ & 22 & 39.17 & 29 & 60.83 \\
\hline$>50$ & 11 & 60.93 & 14 & 39.07 \\
\hline Ethnicity & & & & \\
\hline Chinese & 17 & 41.61 & 25 & 58.39 \\
\hline Malay & 20 & 47.25 & 22 & 52.75 \\
\hline Indian & 30 & 43.19 & 40 & 56.81 \\
\hline Gender & & & & \\
\hline Male & 31 & 43.44 & 34 & 56.56 \\
\hline Female & 39 & 41.32 & 58 & 58.68 \\
\hline Marital Status & & & & \\
\hline Single & 25 & 35.64 & 37 & 64.36 \\
\hline Married & 38 & 47.59 & 44 & 52.41 \\
\hline Others & 7 & 45.8 & 11 & 54.2 \\
\hline Education & & & & \\
\hline Primary/Secondary & 26 & 35.86 & 46 & \\
\hline Post-Secondary & 44 & 45.79 & 46 & \\
\hline Employment & & & & \\
\hline Employed & 48 & 43.89 & 63 & 56.11 \\
\hline Economically inactive & 11 & 54.15 & 10 & 45.85 \\
\hline Unemployed & 6 & 23.46 & 12 & 76.54 \\
\hline Income & & & & \\
\hline$<\$ S G D 20,000$ & 36 & 36.25 & 50 & 63.75 \\
\hline \$SGD 20,000-50,000 & 23 & 52.01 & 31 & 47.99 \\
\hline$>\$ S G D 50,000$ & 6 & 26.06 & 9 & 73.94 \\
\hline & & & & \\
\hline
\end{tabular}

Table 1 presents the frequencies and the weighted percentage of socio-demographic variables by symptom severity. Relatively higher proportions of respondents with severe symptom severity were seen among females, those who were single, had primary/secondary education and were unemployed. However, none of the socio demographic variables significantly predicted symptom severity.

\subsection{Functional Disability}

Table-2. Functional disability (SDS score) by symptom severity of MDD

\begin{tabular}{|c|c|c|c|c|c|}
\hline \multirow[b]{3}{*}{ Functional Disability(SDS Scale) } & \multicolumn{4}{|c|}{ Symptom Severity } & \multirow[b]{3}{*}{ P Value } \\
\hline & \multicolumn{2}{|c|}{ Mild to Moderate } & \multicolumn{2}{|c|}{ Severe } & \\
\hline & Mean & SD & Mean & SD & \\
\hline Home & 3.76 & 2.25 & 5.60 & 2.70 & $0.0002 *$ \\
\hline Work & 3.68 & 2.30 & 5.12 & 2.65 & $0.0114^{*}$ \\
\hline Relationship & 3.01 & 2.39 & 4.79 & 2.90 & $0.0006^{*}$ \\
\hline Social & 3.39 & 2.40 & 5.10 & 3.05 & $0.0034 *$ \\
\hline Overall & 13.82 & & 20.61 & & $<0.001^{*}$ \\
\hline $\begin{array}{l}\text { Number of days in unable to work } \\
\text { or carry out normal activities } \\
\text { because of depressive symptoms }\end{array}$ & 15.43 & 47.26 & 37.95 & 64.40 & 0.0916 \\
\hline
\end{tabular}

Respondents with severe symptoms scored significantly higher in disability than respondents with mild to moderate symptoms in all 4 domains of SDS; home $(\mathrm{P}<0.01)$, work $(\mathrm{P}<0.05)$, relationship $(\mathrm{P}<0.01)$ and social $(\mathrm{P}<0.01)$. Similarly, respondents with severe symptoms also had significantly higher overall SDS score than respondents with mild to moderate symptoms $(\mathrm{P}<0.001)$. Respondents with severe symptoms had a higher mean for the number of days in the past year when they were unable to work or carry out their normal activities due to their depressive symptoms than those with mild to moderate symptoms; however this result did not reach significance. Means and standard deviations are presented in Table 2. 
Sumerianz Journal of Medical and Healthcare

Table-3. Functional disability (SDS score) and presence of MDD symptoms

\begin{tabular}{l|l|l|l}
\hline Presence of Symptom & Absence & Present & \\
\hline Functional Disability (SDS Scale) & Mean & Mean & P value \\
\hline Loss of Interest & & & \\
\hline Home & 3.91 & 4.81 & 0.0765 \\
\hline Work & 3.18 & 4.63 & $0.0039^{*}$ \\
\hline Relationship & 2.62 & 4.44 & $0.0005^{*}$ \\
\hline Social & 2.56 & 4.71 & $0.0001^{*}$ \\
\hline Psychomotor Retardation & & & \\
\hline Home & 4.04 & 5.33 & $0.0015^{*}$ \\
\hline Work & 3.73 & 5.09 & $0.0006^{*}$ \\
\hline Relationship & 3.42 & 4.85 & $0.0008^{*}$ \\
\hline Social & 3.72 & 4.96 & $0.0054^{*}$ \\
\hline Loss of Energy & & & \\
\hline Home & 4.20 & 4.74 & 0.2831 \\
\hline Work & 3.51 & 4.56 & $0.0334^{*}$ \\
\hline Relationship & 3.36 & 4.26 & 0.0839 \\
\hline Social & 3.14 & 4.59 & $0.0074^{*}$ \\
\hline Suicidal thoughts & & & \\
\hline Home & 4.03 & 5.20 & $0.0041^{*}$ \\
\hline Work & 4.10 & 4.56 & 0.2626 \\
\hline Relationship & 3.56 & 4.52 & $0.0251^{*}$ \\
\hline Social & 3.71 & 4.77 & $0.0184^{*}$ \\
\hline Sleep disturbance during night & & & \\
\hline Home & 3.21 & 4.79 & $0.035^{*}$ \\
\hline Work & 4.23 & 4.36 & 0.8626 \\
\hline Relationship & 2.57 & 4.23 & $0.0305^{*}$ \\
\hline Social & 3.71 & 4.36 & 0.4273 \\
\hline Weight decrease & & & \\
\hline Home & 3.86 & 4.89 & 0.0538 \\
\hline Work & 4.14 & 4.52 & 0.4618 \\
\hline Relationship & 3.41 & 4.25 & 0.1208 \\
\hline Social & 3.27 & 4.54 & $0.0211^{*}$ \\
\hline & & & \\
\hline
\end{tabular}

*P value $<0.05$

Respondents who exhibited psychomotor retardation scored significantly higher in disability than those without the symptom in all 4 SDS domains, while respondents who had loss of interest and suicidal thoughts scored significantly higher in disability than those without the symptom in all 4 SDS domains except for home and work respectively. As compared with those without the symptoms, respondents who experienced loss of energy scored significantly higher in disability in the work and social domain, respondents who suffered sleep disturbance during night scored significantly higher in disability in home and relationship domain, and respondents who experience weight decrement scored significantly higher in disability in the social domain of SDS (Table 3).

\subsection{Co-morbidity}

Table-4. Co-morbidity by symptom severity of MDD

\begin{tabular}{l|l|l|l|l|l}
\hline \multicolumn{5}{|l|}{ Symptom Severity } & \\
\hline & \multicolumn{4}{l|}{ Mild to Moderate } & \multicolumn{2}{l|}{ Severe } & \\
\hline Co-morbidity & $\mathrm{n}$ & Weighted \% & $\mathrm{n}$ & Weighted \% & P Value \\
\hline Psychiatric & & & & & \\
\hline Yes & 18 & 27.61 & 31 & 25.34 & 0.5848 \\
\hline No & 52 & 72.39 & 61 & 74.66 & \\
\hline $\begin{array}{l}\text { Chronic } \\
\text { Physical }\end{array}$ & & & & & \\
\hline Yes & 34 & 54.25 & 33 & 38.65 & 0.5738 \\
\hline No & 36 & 45.75 & 59 & 61.35 & \\
\hline
\end{tabular}

Table 4 presents the frequencies and the weighted percentage of chronic physical and psychiatric co-morbidity in those with 12-months MDD by symptom severity. No significant differences were found in the prevalence of either chronic physical or psychiatric illnesses between respondents with different symptom severities. 
Sumerianz Journal of Medical and Healthcare

Table-5. Presence of MDD symptoms and psychiatric co-morbidity

\begin{tabular}{|c|c|c|c|}
\hline \multicolumn{4}{|l|}{ Psychiatric Co-morbidity } \\
\hline & Not Present & Present & \\
\hline Positive Symptoms & Percentage, $\%$ & Percentage, $\%$ & $\mathrm{P}$ value \\
\hline Depressed mood & 94.12 & 96.88 & 0.533 \\
\hline Loss of interest & 80.15 & 78.13 & 0.798 \\
\hline Psychomotor retardation & 46.32 & 40.63 & 0.105 \\
\hline Loss of energy & 77.21 & 84.38 & 0.370 \\
\hline Sense of worthlessness & 71.11 & 71.88 & 0.932 \\
\hline Loss of concentration & 83.82 & 90.63 & 0.331 \\
\hline Suicidal thoughts & 47.41 & 68.75 & $0.030 *$ \\
\hline Feeling restless & 66.18 & 65.63 & 0.953 \\
\hline \multicolumn{4}{|l|}{ Sleep difficulties } \\
\hline Falling asleep & 81.75 & 84.38 & 0.727 \\
\hline Sleep during night & 90.44 & 93.75 & 0.555 \\
\hline Wake up early & 59.56 & 75.00 & 0.105 \\
\hline Sleep too much & 15.33 & 21.88 & 0.370 \\
\hline \multicolumn{4}{|l|}{ Change in appetite } \\
\hline Increased appetite & 75.00 & 85.71 & 0.287 \\
\hline Decreased appetite & 45.10 & 76.92 & $0.040 *$ \\
\hline \multicolumn{4}{|l|}{ Change in weight } \\
\hline Decreased weight & 69.57 & 88.24 & 0.110 \\
\hline Increased weight & 35.19 & 87.50 & $0.000 *$ \\
\hline
\end{tabular}

Significantly higher proportions of psychiatric co-morbid illness were seen among respondents with suicidal thoughts, decreased appetite and increased weight (Table 5).

Table-6. Presence of MDD symptoms and chronic physical co-morbidity

\begin{tabular}{|c|c|c|c|}
\hline \multicolumn{4}{|c|}{ Chronic Physical Co-morbidity } \\
\hline & Not Present & Present & \\
\hline Positive Symptoms & Percentage, $\%$ & Percentage. $\%$ & $\mathrm{P}$ value \\
\hline Depressed mood & 94.17 & 95.38 & 0.734 \\
\hline Loss of interest & 85.44 & 70.77 & $0.021 *$ \\
\hline Psychomotor retardation & 64.47 & 35.53 & 0.444 \\
\hline Loss of energy & 80.58 & 75.38 & 0.424 \\
\hline Sense of worthlessness & 73.53 & 67.69 & 0.416 \\
\hline Loss of concentration & 84.47 & 86.15 & 0.765 \\
\hline Suicidal thoughts & 58.14 & 41.86 & 0.422 \\
\hline Feeling restless & 61.26 & 38.74 & 0.986 \\
\hline \multicolumn{4}{|l|}{ Sleep difficulties } \\
\hline Falling asleep & 83.50 & 80.30 & 0.596 \\
\hline Sleep during night & 91.18 & 90.91 & 0.953 \\
\hline Wake up early & 62.14 & 63.08 & 0.902 \\
\hline Sleep too much & 16.50 & 16.67 & 0.978 \\
\hline \multicolumn{4}{|l|}{ Change in appetite } \\
\hline Increased appetite & 75.29 & 79.17 & 0.612 \\
\hline Decreased appetite & 46.15 & 60.00 & 0.280 \\
\hline \multicolumn{4}{|l|}{ Changes in weight } \\
\hline Decreased weight & 66.29 & 83.72 & $0.037 *$ \\
\hline Increased weight & 30.23 & 74.07 & $0.000^{*}$ \\
\hline
\end{tabular}

Significantly higher proportion of co-morbid chronic physical illnesses were seen among respondents who experienced decrease and increase in weight, while significant lower proportion co-morbid chronic physical illness were seen among those with loss of interest (Table 6).

\section{Discussion}

Amongst 162 Iran residents with 12-months MDD, 43.2\% met the criteria for having mild to moderate symptoms, while $56.8 \%$ met criteria for having severe symptoms. No differences were identified in the sociodemographic variables between the two groups. Our study found that those who exhibit severe symptoms demonstrated significantly higher functional disability overall and within all domains including home, work, relationship and social than those with mild to moderate symptoms. This finding was consistent with previous studies that found severity of symptoms to be associated with more severe functional disability [4, 6]. According to 


\section{Sumerianz Journal of Medical and Healthcare}

Fried and Nesse [7],, many MDD symptoms are individually associated with functional disability, with some symptoms affecting certain functional domains more than the others. Similarly, the current study found that those with symptoms such as loss of interest, psychomotor retardation, loss of energy, suicidal tendencies, sleep disturbance during night and decreased weight had more disability in various respective functional domains. Those who experienced loss of interest suffered more functional disability in the domains of work, relationship and social. Interest is an emotion that motivates learning and exploration of novel things, places and experiences [21]. According to the theory of planned behaviour, intention, a representation of a person's motivation towards a goal, has great influence over outcome behaviours [22, 23]. Therefore, those who experience loss of interest may have reduced motivation and participate less frequently in social and leisure activities involving learning new things, meeting new people and gaining new experiences. Also, a meta-analysis was performed on 60 studies which explored the connection between interest and job performance. It was suggested that those with higher interest are more likely to have better job performance, especially if the interest and occupation were in congruence [24]. Hence, loss of interest in general can contribute to poorer job performance regardless of whether interest and occupation matches. Our study also found that those who experienced psychomotor retardation suffered from severe disability in all 4 domains of SDS. Psychomotor retardation is characterised by decrease in motor activity, speech abnormalities, poor maintenance of eye contact, lack of facial expression, slowing of physical movement, and longer information processing time [25, 26] . Naismith, et al. [27], established a connection between decreased psychomotor speed and increased disability in physical activity, maintaining hobbies and carrying out daily routine. Also, psychomotor ability was found to be predictive of performance for less complex jobs [28]. Furthermore, eye contact, facial expression and speech were important components of social interaction [29, 30]. With many connections to the various domains of functionality, reduced capability in psychomotor ability can be detrimental to one's overall functioning. Our study also found that those who experienced loss of energy were more functionally impaired in work and social domains. Consistently, a longitudinal study found that lack of energy was strongly associated with decreased work productivity, higher rate of absenteeism and poorer social functioning at both baseline and 3-months follow-up of depressive patients undergoing treatment [31]. In addition, the same study found strong connection between change in energy and improved work productivity, which further highlights the importance of energy in work functionality [31]. Those with sleep disturbance during night time were also linked to functional impairment in the home and relationship domains. A review concluded that poor sleep quality was correlated to increased hostility and aggression [32]. Aggression can not only lead to social rejection but also cognitive bias that promotes aggressive behaviour towards others, contributing to poor social interactions [33]. It was also postulated that poor sleep quality can cause deficits in cognitive function including information processing, planning, decision making and attention, which are vital for self-care. Lastly, those experiencing weight loss were also found to have more disability in the social domain of the SDS scale. Consuming lower than required total dietary energy is a major factor in weight loss [34]. As physical activities are strongly tied to dietary consumption, it is possible that insufficient food intake not only reduces the body weight of people with depression but also reduces their participation in leisure and social activities [35] . As mentioned previously, symptom severity is determined by both the count and the intensity of these symptoms; therefore MDD patients who exhibit a wide range of these symptoms with considerable intensity can lead to overall functional disability and across all of its domains.

A prior study found that MDD patients with more severe symptoms were more likely to have at least one comorbid psychiatric disorder [8]. On the contrary, our study found no differences in the prevalence of psychiatric comorbidity between the symptom severities. This perhaps suggests that symptom severity of MDD may not be the best predictor for the prevalence of co-morbid psychiatric illness amongst people with MDD. Nevertheless, other factors such as having shared genetic and risk factors and overlapping symptoms among psychiatric illness may better predict the prevalence of co-morbid psychiatric illness [36-39] .

Despite the lack of association between symptom severity and prevalence of co-morbid psychiatric illnesses, our study found that those who experience MDD symptoms such as suicidal thoughts, loss of appetite and increased weight were more likely to have at least one co-morbid psychiatric illness. It was postulated that the urge to escape from distress is a driving force toward suicide [40]. Angst, et al. [41], found that an increasing number of co-morbid psychiatric disorders were associated with greater subjective distress, work impairment and quality of life. Therefore, those with co-morbid psychiatric illnesses may suffer from greater distress and in turn are more likely to have suicidal thoughts. In addition, studies also found that both dissatisfaction with self-perceived body image and weight gain not only contribute to depression but also anxiety [42, 43]. Hence, increase in weight may contribute to the prevalence of psychiatric co-morbid illnesses, especially GAD. Studies have established the link between presence of MDD and the prevalence of co-morbid chronic physical illness. It was suggested that people with MDD are less likely to engage in physical activity and have poorer diet quality which increases the risk of developing chronic physical illness [11-13]. However, our study did not find significant differences in the prevalence of chronic physical illnesses based on symptom severity. One possibility is that the presence of MDD and the symptoms are more predictive of health risk behaviours such as lack of physical activity as compared to symptoms severity [13]. Furthermore, it is possible that hitherto unknown genetic and other biological factors may play a bigger role in the development of co-morbid chronic physical illness.

Our study found that those with decreased or increased weight were more likely to have at least one co-morbid chronic physical illness, while those with loss of interest were less likely to have any co-morbid chronic physical illness. It is well established that being overweight is a major risk factor for chronic physical illnesses such as diabetes, and cardiovascular and musculoskeletal diseases [44, 45]. Pre-existing chronic physical illnesses such as cancer, heart diseases and neurological diseases including Parkinson's disease and dementia, and their treatments can result in weight loss and malnutrition [46-48]. Hence, weight change in both directions can be predictive of co- 


\section{Sumerianz Journal of Medical and Healthcare}

morbid chronic physical illnesses. As mentioned previously, loss of interest reduces motivation and limits outcome behaviours. Therefore, there is a possibility that those who experience loss of interest may have low motivation towards taking care of one's health and limits the utilization of health care services which leave illness undiagnosed. However, more research is required to support this possibility.

There are limitations to this study. Our study examines the data from a subset of the SMHS sample; hence the sample size is small. Due to insufficient sample size, the categories of the symptom severity adopted by HAMD were combined to form 2 broad categories. Our study was also unable to assess the prevalence of each specific comorbid psychiatric and chronic physical illness among respondents with MDD because of the small sample size. Hence, this restricted the depth of our analysis. Therefore, a more focused study design with a larger sample is needed to better understand the relationship between symptom severity of MDD, functional disability and prevalence of co-morbid psychiatric and chronic physical illness. Next, our study did not take into consideration the sequence of onset of MDD and the co-morbid illnesses. Studies suggest that MDD has a bidirectional relationship with both comorbid psychiatric and chronic physical illnesses $[49,50]$. Hence, it is possible that the symptom severity of MDD could be predictive of co-morbid illness depending on the onset sequence of MDD. Consequently, future studies could examine the association of symptom severity of MDD and prevalence of co-morbid psychiatric and chronic physical illness, in relation to the age of onset of the conditions.

In conclusion, our findings highlight the importance of managing symptoms of MDD in order to minimize the detrimental impact on functional ability among Singapore residents with MDD. Furthermore, some MDD symptoms such as loss of interest and psychomotor retardation, as opposed to others, were more predictive of functional disability in specific domains. Additionally, some MDD symptoms like increase/decrease of weight are also more predictive of medical co-morbidities than others. Therefore, this emphasizes the need for clinicians to check for medical co-morbidities when patients present with the constellation of these symptoms.

\subsection{Conflict of Interest}

The authors declare that there are no potential conflicts of interest with respect to the research, authorship and/or publication of this article.

\subsection{Ethics Approval and Consent to Participate}

Approval for the study was granted by the institutional ethics committee: the National Healthcare Group, Domain Specific Review Board. Informed consent was obtained from the participants preceding the survey and the examination.

\section{Reference}

[1] Cassano, P. and Fava, M., 2002. "Depression and public health." Journal of Psychosomatic Research, vol. 53, pp. 849-57.

[2] WHO, 2017. Depression and other common mental disorders: Global health estimates. World Health Organization.

[3] Ishak, W. W., Greenberg, J. M., Balayan, K., Kapitanski, N., Jeffrey, J., and Fathy, H., 2011. "Quality of life: the ultimate outcome measure of interventions in major depressive disorder." Harvard Review of Psychiatry, vol. 19, pp. 229-39.

[4] Judd, L. L., Akiskal, H. S., Zeller, P. J., Paulus, M., Leon, A. C., and Maser, J. D., 2000. "Psychosocial disability during the long-term course of unipolar major depressive disorder." Archives of General Psychiatry, vol. 57, pp. 375-80.

[5] Oquendo, M. A., Galfalvy, H., Russo, S., Ellis, S. P., Grunebaum, M. F., and Burke, A., 2004. "Prospective study of clinical predictors of suicidal acts after a major depressive episode in patients with major depressive disorder or bipolar disorder." American Journal of Psychiatry, vol. 161, pp. 1433-41.

[6] Ormel, J., Von Korff, M., Van den Brink, W., Katon, W., Brilman, E., and Oldehinkel, T., 1993. "Depression, anxiety, and social disability show synchrony of change in primary care patients." American Journal of Public Health, vol. 83, pp. 385-90.

[7] Fried, E. I. and Nesse, R. M., 2014. "The impact of individual depressive symptoms on impairment of psychosocial functioning." PloS one, vol. 9, p. 90311.

[8] Kessler, R. C., Berglund, P., Demler, O., Jin, R., Koretz, D., and Merikangas, K. R., 2003. "The epidemiology of major depressive disorder, Results from the National Comorbidity Survey Replication NCS-R." Jama., vol. 289, pp. 3095-105.

[9] Thaipisuttikul, P., Ittasakul, P., Waleeprakhon, P., Wisajun, P., and Jullagate, S., 2014. "Psychiatric comorbidities in patients with major depressive disorder." Neuropsychiatr Dis Treat., vol. 10, pp. 2097-103.

[10] Noël, P. H., Williams, J. W., Unützer, J., Worchel, J., Lee, S., and Cornell, J., 2004. "Depression and comorbid illness in elderly primary care patients: impact on multiple domains of health status and wellbeing." The Annals of Family Medicine, vol. 2, pp. 555-62.

[11] Katon, W. J., 2003. "Clinical and health services relationships between major depression, Depressive symptoms, And general medical illness." Biological Psychiatry, vol. 54, pp. 216-26.

[12] Pereira, S. M. P., Geoffroy, M. C., and Power, C., 2014. "Depressive symptoms and physical activity during 3 decades in adult life, Bidirectional associations in a prospective cohort study." JAMA Psychiatry, vol. 71, pp. 1373-80. 


\section{Sumerianz Journal of Medical and Healthcare}

[13] Appelhans, B. M., Whited, M. C., Schneider, K. L., Ma, Y., Oleski, J. L., and Merriam, P. A., 2012. "Depression severity, Diet quality, And physical activity in women with obesity and depression." Journal of the Academy of Nutrition and Dietetics, vol. 112, pp. 693-8.

[14] Wong, W. K., 2011. Census of population 2010, Demographic characteristics, Education, Language and religion, Statistical release 1. Ministry of Trade and Industry. Singapore: Dept. of Statistics.

[15] Chong, S. A., Vaingankar, J., Abdin, E., and Subramaniam, M., 2012. "The prevalence and impact of major depressive disorder among Chinese, Malays and Indians in an Asian multi-racial population." Journal of Affective Disorders, vol. 138, pp. 128-36.

[16] Subramaniam, M., Vaingankar, J., Heng, D., Kwok, K. W., Lim, Y. W., and Yap, M., 2012. "The Singapore mental health study, An overview of the methodology." International Journal of Methods in Psychiatric Research, vol. 21, pp. 149-57.

[17] Kessler, R. C. and Üstün, T. B., 2004. "The world mental health (WMH) survey initiative version of the world health organization (WHO) composite international diagnostic interview CIDI,." International Journal of Methods in Psychiatric Research, vol. 13, pp. 93-121.

[18] Rush, A. J., Trivedi, M. H., Ibrahim, H. M., Carmody, T. J., Arnow, B., and Klein, D. N., 2003. "The 16item quick inventory of depressive symptomatology QIDS, Clinician rating QIDS-C, And self-report QIDSSR, A psychometric evaluation in patients with chronic major depression." Biological Psychiatry, vol. 54, pp. 573-83.

[19] Hamilton, M., 1960. "A rating scale for depression." Journal of Neurology, Neurosurgery, and Psychiatry, vol. 23 , p. 56.

[20] Leon, A. C., Olfson, M., Portera, L., Farber, L., and Sheehan, D. V., 1997. "Assessing psychiatric impairment in primary care with the Sheehan Disability Scale." The International Journal of Psychiatry in Medicine, vol. 27, pp. 93-105.

[21] Silvia, P. J., 2008. "Interest-The curious emotion." Current Directions in Psychological Science, vol. 17, pp. 57-60.

[22] Ajzen, I., 1991. "The theory of planned behavior." Organizational Behavior and Human Decision Processes, vol. 50, pp. 179-211.

[23] Conner, M. and Armitage, C. J., 1998. "Extending the theory of planned behavior, A review and avenues for further research." Journal of Applied Social Psychology, vol. 28, pp. 1429-64.

[24] Nye, C. D., Su, R., Rounds, J., and Drasgow, F., 2012. "Vocational interests and performance, A quantitative summary of over 60 years of research." Perspectives on Psychological Science, vol. 7, pp. 384403.

[25] Buyukdura, J. S., McClintock, S. M., and Croarkin, P. E., 2011. "Psychomotor retardation in depression, Biological underpinnings, Measurement, And treatment." Progress in Neuro-Psychopharmacology and Biological Psychiatry, vol. 35, pp. 395-409.

[26] Sobin, C. and Sackeim, H. A., 1997. "Psychomotor symptoms of depression." The American Journal of Psychiatry, vol. 154, p. 4.

[27] Naismith, S. L., Longley, W. A., Scott, E. M., and Hickie, I. B., 2007. "Disability in major depression related to self-rated and objectively-measured cognitive deficits: a preliminary study." BMC Psychiatry, vol. 7, p. 32.

[28] Fine, S. A., 1955. "A structure of worker functions." Journal of Counseling \& Development, vol. 34, pp. 66-73.

[29] Argyle, M. and Dean, J., 1965. "Eye-contact, distance and affiliation." Sociometry, pp. 289-304.

[30] Buck, R. W., Savin, V. J., Miller, R. E., and Caul, W. F., 1972. "Communication of affect through facial expressions in humans." Journal of Personality and Social Psychology, vol. 23, p. 362.

[31] Swindle, R., Kroenke, K., and Braun, L., 2001. Energy and improved workplace productivity in depression. Investing in health, The social and economic benefits of health care innovation. Emerald Group Publishing Limited, pp. 323-41.

[32] Kamphuis, J., Meerlo, P., Koolhaas, J. M., and Lancel, M., 2012. "Poor sleep as a potential causal factor in aggression and violence." Sleep medicine, vol. 13, pp. 327-34.

[33] DeWall, C. N., Twenge, J. M., Gitter, S. A., and Baumeister, R. F., 2009. "It's the thought that counts, The role of hostile cognition in shaping aggressive responses to social exclusion." Journal of Personality and Social Psychology, vol. 96, p. 45.

[34] Andreyeva, T., Long, M. W., Henderson, K. E., and Grode, G. M., 2010. "Trying to lose weight, Diet strategies among Americans with overweight or obesity in 1996 and 2003." Journal of the Academy of Nutrition and Dietetics, vol. 110, pp. 535-42.

[35] Melzer, K., Kayser, B., Saris, W. H., and Pichard, C., 2005. "Effects of physical activity on food intake." Clinical Nutrition, vol. 24, pp. 885-95.

[36] Angold, A., Costello, E. J., and Erkanli, A., 1999. "Comorbidity." Journal of Child Psychology and Psychiatry, vol. 40, pp. 57-87.

[37] Gorwood, P., 2004. "Generalized anxiety disorder and major depressive disorder comorbidity, An example of genetic pleiotropy?" European Psychiatry, vol. 19, pp. 27-33.

[38] Mathew, A., Pettit, J., Lewinsohn, P., Seeley, J., and Roberts, R., 2011. "Co-morbidity between major depressive disorder and anxiety disorders, Shared etiology or direct causation?" Psychological Medicine, vol. 41, pp. 2023-34. 


\section{Sumerianz Journal of Medical and Healthcare}

[39] Thapar, A. and McGuffin, P., 1997. "Anxiety and depressive symptoms in childhood-a genetic study of comorbidity." Journal of Child Psychology and Psychiatry, vol. 38, pp. 651-6.

[40] Nock, M. K., Hwang, I., Sampson, N. A., and Kessler, R. C., 2010. "Mental disorders, Comorbidity and suicidal behavior, Results from the National Comorbidity Survey Replication." Molecular Psychiatry, vol. 15, p. 868.

[41] Angst, J., Sellaro, R., and Merikangas, K. R., 2002. "Multimorbidity of psychiatric disorders as an indicator of clinical severity." European Archives of Psychiatry and Clinical Neuroscience, vol. 252, pp. 147-54.

[42] Kostanski, M. and Gullone, E., 1998. "Adolescent body image dissatisfaction, Relationships with selfesteem, Anxiety, And depression controlling for body mass." The Journal of Child Psychology and Psychiatry and Allied Disciplines, vol. 39, pp. 255-62.

[43] Rofey, D. L., Kolko, R. P., Iosif, A. M., Silk, J. S., Bost, J. E., and Feng, W., 2009. "A longitudinal study of childhood depression and anxiety in relation to weight gain." Child Psychiatry and Human Development, vol. 40, pp. 517-26.

[44] Ringbäck, W. G., Eliasson, M., and Rosén, M., 2008. "Underweight, Overweight and obesity as risk factors for mortality and hospitalization." Scandinavian Journal of Public Health, vol. 36, pp. 169-76.

[45] Seidell, J. C., De Groot, L. C., Van Sonsbeek, J., Deurenberg, P., and Hautvast, J., 1986. "Associations of moderate and severe overweight with self-reported illness and medical care in Dutch adults." American Journal of Public Health, vol. 76, pp. 264-9.

[46] Flegal, K. M., Graubard, B. I., Williamson, D. F., and Cooper, R. S., 2010. "Reverse causation and illnessrelated weight loss in observational studies of body weight and mortality." American Journal of Epidemiology, vol. 173, pp. 1-9.

[47] Norman, K., Pichard, C., Lochs, H., and Pirlich, M., 2008. "Prognostic impact of disease-related malnutrition." Clinical Nutrition, vol. 27, pp. 5-15.

[48] Ross, P., Ashley, S., Norton, A., Priest, K., Waters, J., and Eisen, T., 2004. "Do patients with weight loss have a worse outcome when undergoing chemotherapy for lung cancers?" British Journal of Cancer, vol. 96, p. 1905.

[49] Brière, F. N., Rohde, P., Seeley, J. R., and Klein, D., 2014. "Lewinsohn PM. Comorbidity between major depression and alcohol use disorder from adolescence to adulthood." Comprehensive Psychiatry, vol. 55, pp. 526-33.

[50] Van Manen, J., Bindels, P., Dekker, F., IJzermans, C., Van der Zee, J., and Schade, E., 2002. "Risk of depression in patients with chronic obstructive pulmonary disease and its determinants." Thorax, vol. 57, pp. 412-6. 